\title{
Optimization of Carbamazepine-Succinic Acid Cocrystal Preparation Using Quality by Design Approach
}

\author{
Yingfan Xia, Chengjun Jiang*, Jinna Zhang \\ School of Biological and Chemical Engineering, Zhejiang University of Science and Technology, Hangzhou, China \\ Email: cecilina.xia@foxmail.com, ‘jcj312@163.com, z2729715823@163.com
}

How to cite this paper: Xia, Y.F., Jiang, C.J. and Zhang, J.N. (2021) Optimization of Carbamazepine-Succinic Acid Cocrystal Preparation Using Quality by Design Approach. Open Access Library Journal, 8: e7074.

https://doi.org/10.4236/oalib.1107074

Received: December 11, 2020

Accepted: February 21, 2021

Published: February 24, 2021

Copyright $\odot 2021$ by author(s) and Open Access Library Inc.

This work is licensed under the Creative Commons Attribution International License (CC BY 4.0).

http://creativecommons.org/licenses/by/4.0/

\begin{abstract}
The present investigation was aimed at using quality by design approach optimization of cocrystal preparation. The challenge was too many factors affect the final purity and yield. Carbamazepine (CBZ)-succinic acid (SA) was selected as a model cocrystal for this study. A Design of Experiments (DoE) approach, specifically Central Composite Design (CCD) with the aid of Response Surface Methodology (RSM) was used to optimize formulation variables for the synthesis of carbamazepine and succinic acid cocrystals using slurry crystallization. Design was applied for studying the effect of four independent variables (time, molar ratio, temperature, and concentration) on the yield. The experimental outcome indicated that the molar ratio significantly affects the yield of the cocrystal. Further, the optimized formulation was characterized by powder X-ray diffraction. It can be found that within a certain range, all obtained are pure cocrystal.
\end{abstract}

\section{Subject Areas \\ Chemical Engineering \& Technology \\ Keywords \\ Quality by Design, Cocrystals, Carbamazepine}

\section{Introduction}

Cocrystallization is a novel method for designing and developing new multi-component crystalline solids with unique packing characteristics [1] [2]. Through the cocrystallization technology to engineer poorly soluble active pharmaceutical ingredients (API), it can provide excellent solubility, stability, better release and therefore higher bioavailability without changing the physiological effects of the 
API degree. Studies have also shown that cocrystals may be helpful in dosage formulations because the multi-component structure of cocrystals can improve mechanical properties and improve powder flow and compressibility [3] [4] [5] [6]. Traditional cocrystallization method is widely used for screening new drug cocrystals [7] including mechanical grinding, cooling and anti-solvent addition methods, Slurry Crystallization and solvent evaporation. However, as far as we know, when one component is water-soluble and the other is water-insoluble, slurry crystallization is more advantageous [8]. However, although the formation of cocrystal is a process of self-assembly between molecules [9]. However, no literature has studied the influence of process parameters on the purity and yield of the final product during the slurry crystallization process [10]. Therefore, it is necessary to conduct systematic research in the field of cocrystal preparation methods and system optimization formula parameters, especially solvent and dosage standards. The introduction of quality of design $(\mathrm{QbD})$ in the pharmaceutical industry helps to understand the attributes related to the formulation and process in the product development process [11] [12] [13]. When producing new products or products on the market, $\mathrm{QbD}$ can help determine the potential risks of various operations in advance to ensure that appropriate control strategies can be applied in time. Since QbD is a science-based method, it uses Design of Experiments (DoE) for the properties of drugs, co-formers and excipients, as well as process parameters to determine and evaluate key quality attributes, thereby providing for optimization and improvement of manufacturing operations. Use response surface methodology in DoE to optimize the process by generating polynomial equations that describe the relationship between input and output. The advantage of this model is that it is easy to understand. Carbamazepine (CBZ)-succinic acid (SA) was used as a model cocrystal for this study. Therefore, there is a need for a systematic study in the field of preparation method for cocrystals and criteria for formulation parameters optimization.

In this study, time, molar ratio, temperature, and concentration are critical process parameters (CPPs); the purity and yield of CBZ-SA cocrystal are critical quality attributes (CQAs). The purpose is to illustrate the correlation between purity and yield through experimental design and mathematical models, establish a design space with multiple indicators overlapping, select a better operating space, and finally perform process verification.

\section{Materials and Methods}

\subsection{Materials}

CBZ and SA were purchased from Energy Chemical (Shanghai, China). HPLC-grade ethanol was purchased from Shanghai Lingfeng Chemical Reagent Co., Ltd. (Shanghai, China).

\subsection{Methods}

\subsubsection{Cocrystal Synthesis}

CBZ-SA cocrystal was synthesized using a slurry crystallization method as pre- 
viously described. Typical, Carbamazepine (236 mg) and succinic acid (118 mg) were precisely weighed and the CAB-SA cocrystal was synthesized using a slurry crystallization.

\subsubsection{Cocrystal Optimization}

A Central Composite Design (CCD) generated using version 8 Design Expert $^{\circledR}$ software (Stat-Ease Inc., Minneapolis, MN, USA) was selected for the optimization of process variables for the synthesis of CBZ-SA cocrystal using slurry crystallization. The experiments conducted for the CCD are listed in Table 1. All experiments were performed in triplicate for each run using the levels suggested by the CCD, which also includes repeated runs at specific levels. Furthermore, the runs are conducted in a randomized manner to minimize any.

According to the existing research results and a large number of analysis comparisons, crystallization temperature, crystallization time, material molar ratio and material concentration are selected as influencing factors, and the yield of CBZ-SA cocrystal is used as the evaluation index (response value). It is confirmed that when the crystallization temperature is $20^{\circ} \mathrm{C}-60^{\circ} \mathrm{C}$, the crystallization time is $2-6 \mathrm{~h}$, the material molar ratio is $1: 3-3: 1$, and the material concentration is $0.1-0.5$, the yield can basically reach the maximum.

The four-factor five-level central comprehensive experimental design method was used to perform quadratic multiple regression equation fitting and optimization analysis. Perform the test according to the factor codes and levels are shown in Table 1.

\subsection{Characterization of Optimized Cocrystal (CBZ-SA)}

X-ray powder diffraction patterns were collected using Ultima IV series X-ray diffraction, $\mathrm{Cu}-\mathrm{K} \alpha$ radiation of $\lambda=0.154 \mathrm{~nm}$ and a nickel filter. Samples were placed onto a silicon wafer slide. Generator settings were $40 \mathrm{kV}$ with a current of $40 \mathrm{~mA}$ used for the measurement. Data were collected $(\mathrm{n}=3)$ in the range $2 \theta=$ $5^{\circ}$ to $40^{\circ}$ at a scanning rate of $5^{\circ} / \mathrm{min}$ with a scan rate of $0.04^{\circ} /$ time and a slit width of $6.0 \mathrm{~mm}$. The X-ray diffraction data were treated using evaluation curve fitting software. Baseline correction was performed on each diffraction pattern by subtracting a spline function fitted to the curved background and the diffraction pattern of uncoated nano cocrystals was used for reference purposes.

Table 1. Response surface design factor.

\begin{tabular}{ccccc}
\hline Level & Time/h & Molar ratio/g. $\mathbf{m L}^{-1}$ & Temperature $/^{\circ} \mathrm{C}$ & Concentration $/ \mathbf{m o l} \cdot \mathrm{L}^{-1}$ \\
\hline 2 & 10 & $3: 1$ & 20 & 0.5 \\
1 & 8 & $2: 1$ & 30 & 0.4 \\
0 & 6 & $1: 1$ & 40 & 0.3 \\
-1 & 4 & $1: 2$ & 50 & 0.2 \\
-2 & 2 & $1: 3$ & 60 & 0.1 \\
\hline
\end{tabular}




\section{Results}

\subsection{Optimization of Cocrystal Preparation}

A summary of the input variables used to optimize the manufacture of cocrystal identified using the CCD is summarized in Table 2.

The test results show that when the conditions of influencing factors are: time $4 \mathrm{~h}$, molar ratio $2: 1$, temperature $30^{\circ} \mathrm{C}$, and concentration $0.4 \mathrm{~mol} \cdot \mathrm{L}^{-1}$, the maximum yield is $84.32 \%$.

Table 2. Central composite experimental design and results.

\begin{tabular}{|c|c|c|c|c|c|}
\hline Experiment order & Time & Molar ratio & Temperature & Concentration & Yield/\% \\
\hline 1 & 1 & 1 & 1 & 1 & 82.20 \\
\hline 2 & -1 & 1 & -1 & 1 & 79.24 \\
\hline 3 & 0 & 0 & 2 & 0 & 61.20 \\
\hline 4 & 2 & 0 & 0 & 0 & 64.50 \\
\hline 5 & 0 & 0 & 0 & 0 & 62.15 \\
\hline 6 & -1 & 1 & -1 & -1 & 68.64 \\
\hline 7 & 1 & 1 & -1 & 1 & 83.05 \\
\hline 8 & 1 & -1 & 1 & -1 & 49.26 \\
\hline 9 & 0 & 0 & 0 & 0 & 66.38 \\
\hline 10 & 1 & 1 & -1 & -1 & 72.46 \\
\hline 11 & -1 & -1 & -1 & -1 & 46.08 \\
\hline 12 & 0 & 0 & 0 & 0 & 62.61 \\
\hline 13 & 0 & 0 & 0 & 0 & 63.56 \\
\hline 14 & 0 & 2 & 0 & 0 & 75.26 \\
\hline 15 & 1 & -1 & 1 & 1 & 64.35 \\
\hline 16 & 0 & 0 & 0 & 0 & 60.26 \\
\hline 17 & 1 & -1 & -1 & 1 & 50.85 \\
\hline 18 & -1 & -1 & 1 & 1 & 59.59 \\
\hline 19 & 0 & 0 & 0 & -2 & 11.30 \\
\hline 20 & 0 & 0 & 0 & 0 & 57.44 \\
\hline 21 & -2 & 0 & 0 & 0 & 47.08 \\
\hline 22 & 0 & -2 & 0 & 0 & 42.37 \\
\hline 23 & 1 & 1 & 1 & -1 & 76.69 \\
\hline 24 & -1 & -1 & 1 & -1 & 49.79 \\
\hline 25 & 0 & 0 & -2 & 0 & 67.78 \\
\hline 26 & -1 & 1 & 1 & -1 & 72.88 \\
\hline 27 & 0 & 0 & 0 & 2 & 72.03 \\
\hline 28 & -1 & -1 & -1 & 1 & 61.18 \\
\hline 29 & -1 & 1 & 1 & 1 & 84.32 \\
\hline 30 & 1 & -1 & -1 & -1 & 41.31 \\
\hline
\end{tabular}




\subsection{Regression Analysis}

Use Design-expert 8 to perform multiple regression fitting on the experimental results in Table 2, and obtain the predicted value of the carbamazepine CBZ-SA yield. The multiple regression model equations of the coding independent variables crystallization temperature, crystallization time, material molar ratio and material concentration are obtained: $\mathrm{R}_{1}=61.86+1.39 \mathrm{~A}+10.95 \mathrm{~B}+0.96 \mathrm{C}+$ $8.71 \mathrm{D}+1.26 \mathrm{AB}+0.84 \mathrm{AC}-0.39 \mathrm{AD}-0.68 \mathrm{BC}-0.71 \mathrm{BD}-0.25 \mathrm{CD}+0.086 \mathrm{~A}^{2}+$ $0.84 \mathrm{~B}^{2}+2.26 \mathrm{C}^{2}-3.45 \mathrm{D}^{2}$.

The results of the analysis of variance are shown in Table 3.

Analysis of variance shows, Model significance of the equation $\mathrm{P}=0.0052<$ $0.05, R^{2}=0.9724$, It shows that the equation has good fit and small experimental error, which can be used to predict and analyze the yield of carbamazepine cocrystal.

The regression equation coefficient significance experiment results show that the first term B has a significant effect on the yield of carbamazepine cocrystal, the interaction term $A B$ is significant, the quadratic terms $C^{2}$ and $D^{2}$ are significant, and the other terms are not significant.

Table 3. Estimation of regression coefficient and analysis of variance in regression equation.

\begin{tabular}{|c|c|c|c|c|c|}
\hline Source & Sum Of Squares & Degree Of Freedom & Mean Square & F-Value & P-Value \\
\hline model & 5391.22 & 14 & 385.09 & 4.09 & 0.0052 \\
\hline A & 46.18 & 1 & 46.18 & 0.49 & 0.4945 \\
\hline B & 2878.76 & 1 & 2878.76 & 30.57 & $<0.0001$ \\
\hline $\mathrm{C}$ & 22.25 & 1 & 22.25 & 0.24 & 0.6339 \\
\hline $\mathrm{D}$ & 1822.31 & 1 & 1822.31 & 19.35 & 0.0005 \\
\hline $\mathrm{AB}$ & 25.48 & 1 & 25.48 & 0.27 & 0.6106 \\
\hline $\mathrm{AC}$ & 11.21 & 1 & 11.21 & 0.12 & 0.7349 \\
\hline $\mathrm{AD}$ & 2.41 & 1 & 2.41 & 0.026 & 0.8750 \\
\hline $\mathrm{BC}$ & 7.38 & 1 & 7.38 & 0.078 & 0.7833 \\
\hline $\mathrm{BD}$ & 8.11 & 1 & 8.11 & 0.086 & 0.7732 \\
\hline $\mathrm{CD}$ & 1.00 & 1 & 1.00 & 0.011 & 0.9195 \\
\hline A2 & 0.20 & 1 & 0.20 & $2.130 \mathrm{E}-003$ & 0.9638 \\
\hline B2 & 19.44 & 1 & 19.44 & 0.21 & 0.6561 \\
\hline $\mathrm{C} 2$ & 140.16 & 1 & 140.16 & 1.49 & 0.2413 \\
\hline D2 & 325.66 & 1 & 325.66 & 3.46 & 0.0827 \\
\hline Residual & 1412.64 & 15 & 94.18 & & \\
\hline Underfitting & 1366.83 & 10 & 136.68 & 14.92 & 0.0040 \\
\hline Pure Error & 45.81 & 5 & 9.16 & & \\
\hline Total Variation & 6803.86 & 29 & & & \\
\hline
\end{tabular}




\subsection{Optimization of the Yield of Carbamazepine Cocrystal}

Use Design-expert 8 software to optimize the multiple regression model of carbamazepine cocrystal yield, and predict that under the optimal crystallization conditions: crystallization time is $4 \mathrm{~h}$, material molar ratio is CBZ:SA $=2: 1$, When the crystallization temperature is $30^{\circ} \mathrm{C}$ and the material concentration is 0.4 , the maximum yield of CBZ-SA cocrystal is $84.32 \%$. For the four factors of crystallization time, crystallization temperature, material molar ratio and material concentration, when two of them are selected as fixed values, the response surface and contour lines of the other two factors and their interaction on the yield of carbamazepine eutectic are as follows: As shown in Figures 1-6, the shape of the contour lines can reflect the strength of the interaction effect. An ellipse indicates a significant interaction effect, while a circle is the opposite.

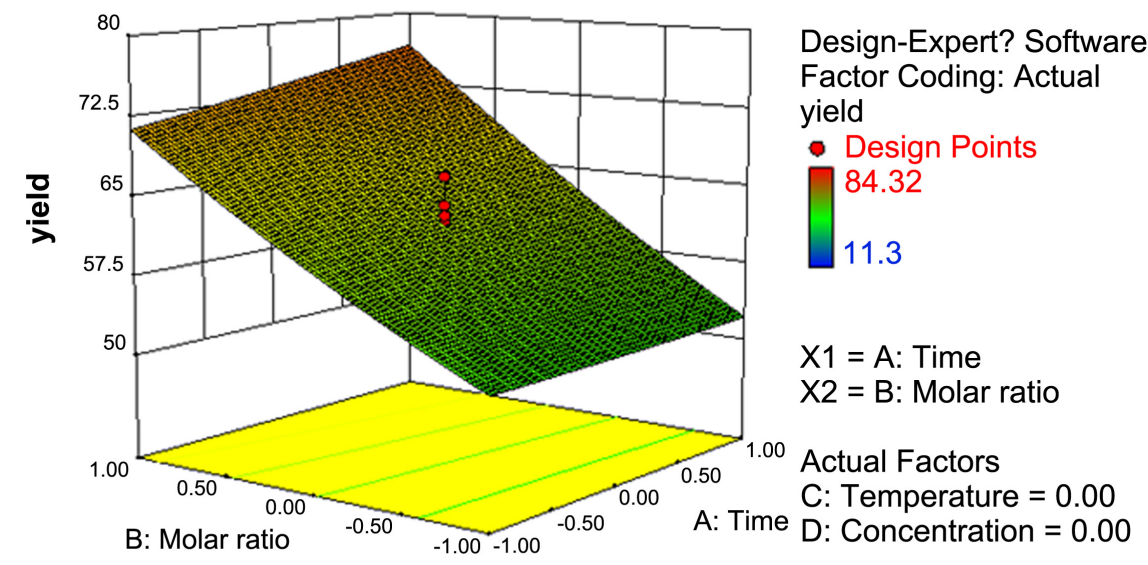

(a)

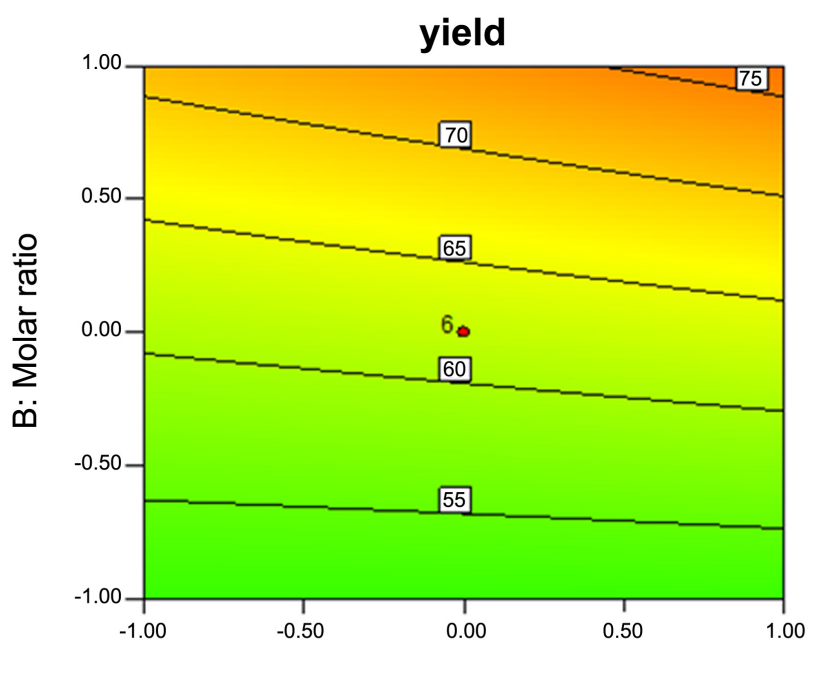

A: Time

(b)

Figure 1. Response surface (a) and contour map (b) of the influence of the interaction of time and molar ratio on yield of CBZ-SA cocrystal. 


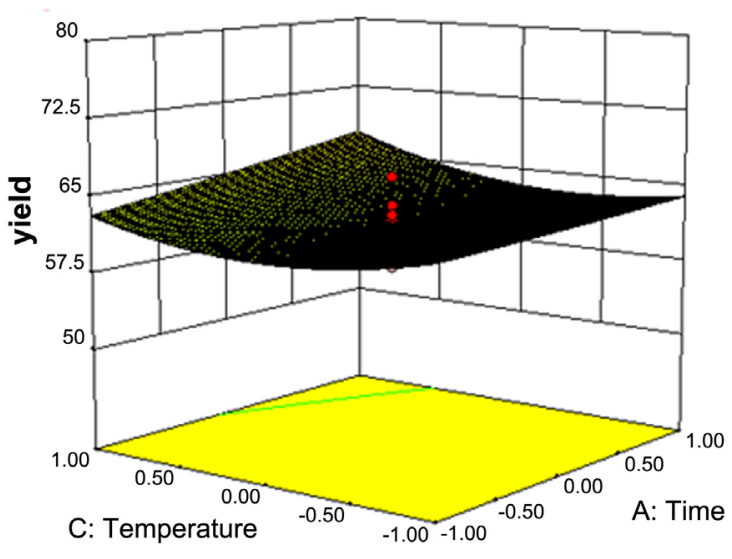

Design-Expert? Software

Factor Coding: Actual yield

- Design Points

84.32

11.3

$\mathrm{X} 1=\mathrm{A}:$ Time

X2 = C: Temperature

Actual Factors

$\mathrm{B}$ : Molar ratio $=0.00$

D: Concentration $=0.00$

(a)

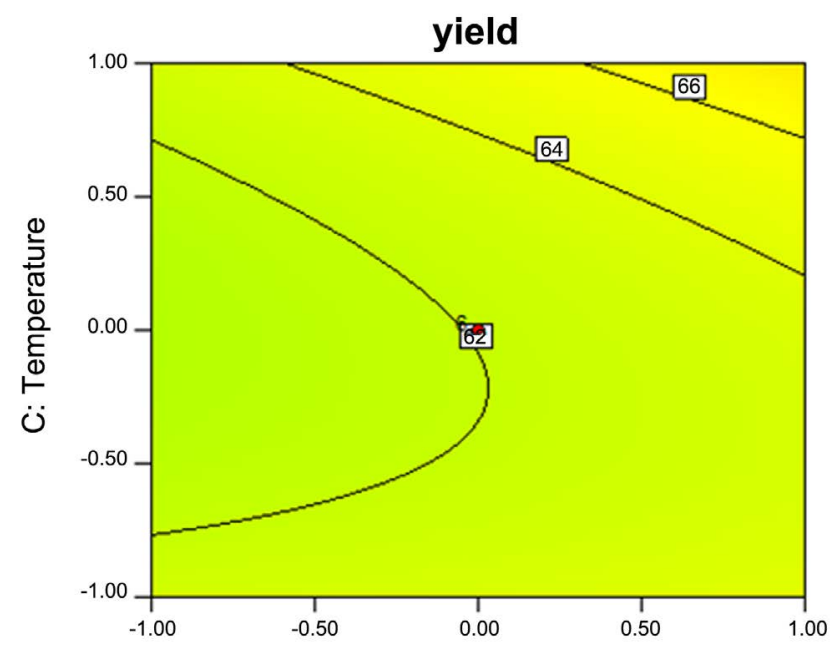

A: Time

(b)

Figure 2. Response surface (a) and contour map (b) of the influence of the interaction of time and temperature on yield of CBZ-SA cocrystal.

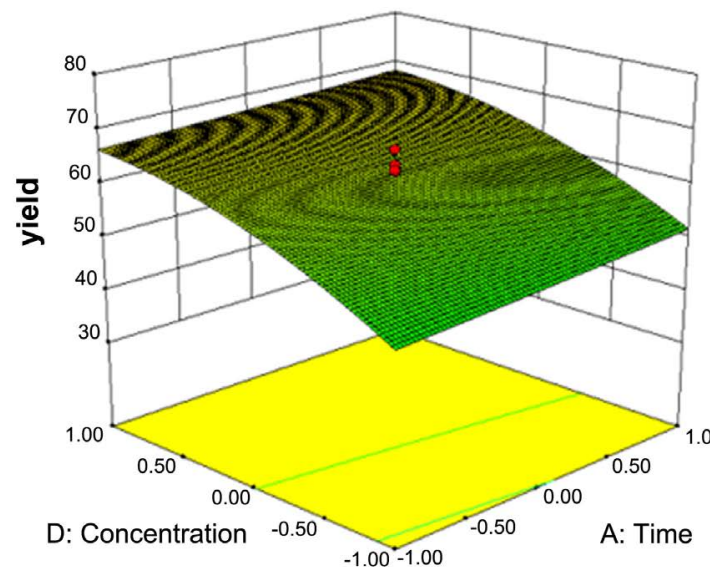

(a)
Design-Expert? Software Factor Coding: Actual yield

- Design Points

84.32

11.3

$\mathrm{X} 1=\mathrm{A}:$ Time X2 = D: Concentration

Actual Factors

B: Molar ratio $=0.00$

C: Temperature $=0.00$ 


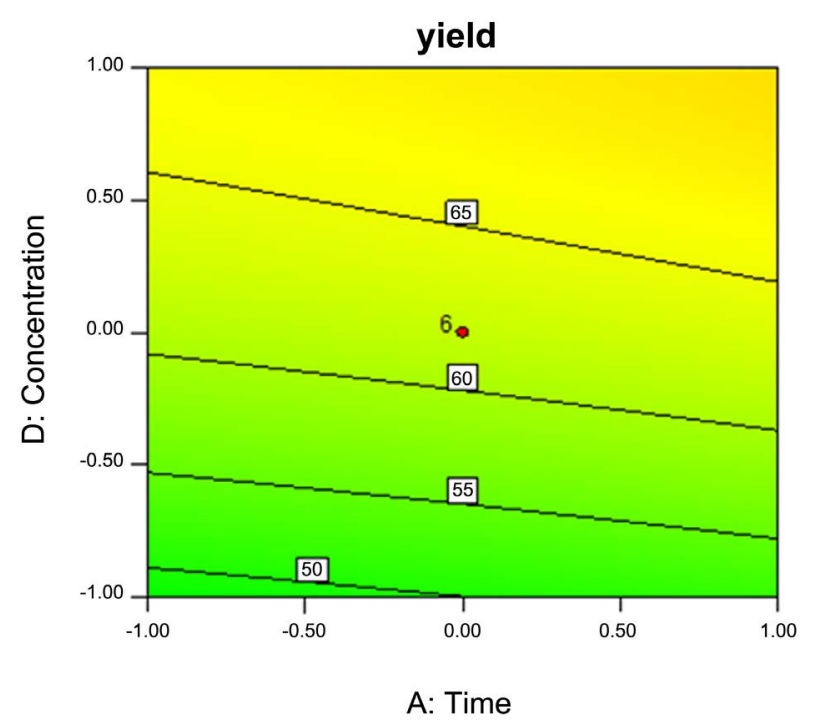

(b)

Figure 3. Response surface (a) and contour map (b) of the influence of the interaction of time and concentration on yield of CBZ-SA cocrystal.

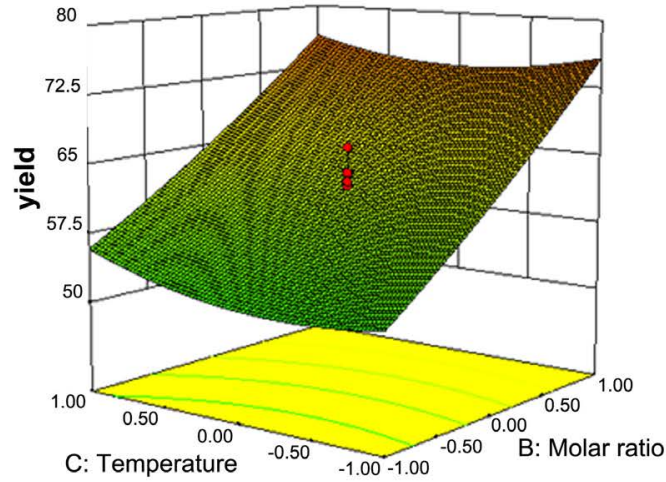

(a)
Design-Expert? Software Factor Coding: Actual yield

- Design Points

84.32

11.3

$\mathrm{X} 1$ = B: Molar ratio

$\mathrm{X} 2$ = $\mathrm{C}:$ Temperature

\section{Actual Factors}

A: Time $=0.00$

D: Concentration $=0.00$

yield

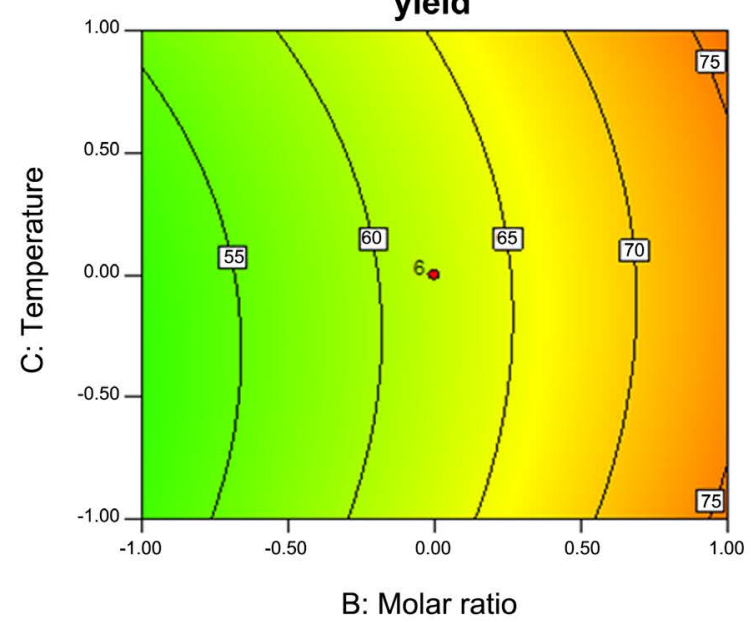

(b)

Figure 4. Response surface (a) and contour map (b) of the influence of the interaction between mole ratio and temperature on yield of CBZ-SA cocrystal. 


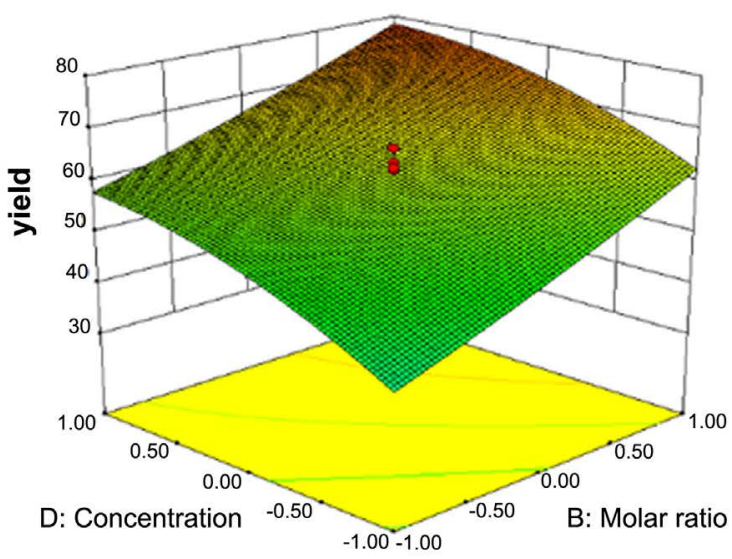

Design-Expert? Software Factor Coding: Actual yield

- Design Points

84.32

11.3

$\mathrm{X} 1=\mathrm{B}:$ Molar ratio X2 = D: Concentration

Actual Factors

A: Time $=0.00$

C: Temperature $=0.00$

(a)

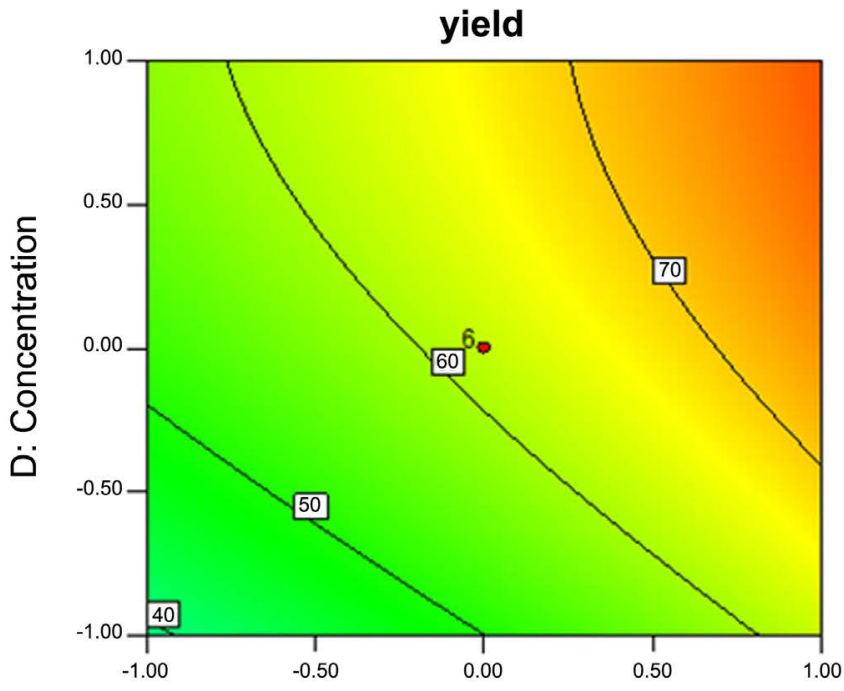

B: Molar ratio

(b)

Figure 5. Response surface (a) and contour plot (b) of the influence of the interaction between molar ratio and concentration on yield of CBZ-SA cocrystal.

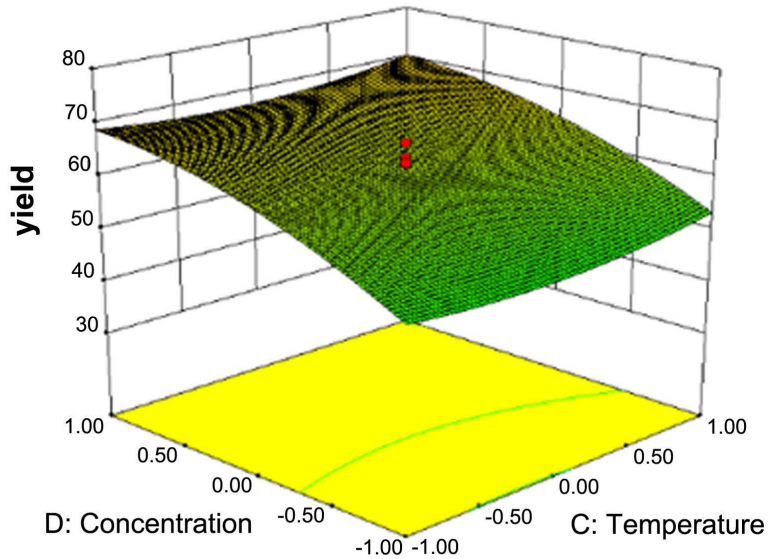

Design-Expert? Software Factor Coding: Actual yield

- Design Points

84.32

11.3

X1 = C: Temperature X2 = D: Concentration

Actual Factors

A: Time $=0.00$

$\mathrm{B}$ : Molar ratio $=0.00$

(a) 


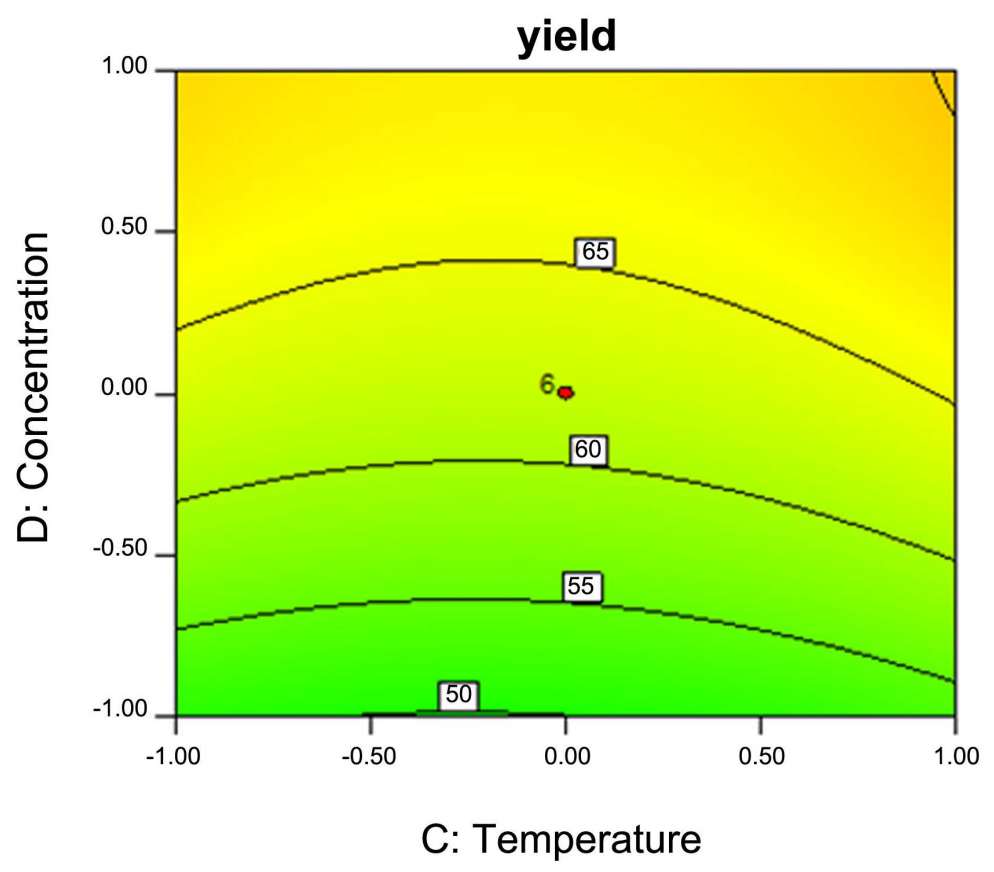

(b)

Figure 6. Response surface (a) and contour map (b) of the influence of temperature and concentration on yield of CBZ-SA cocrystal.

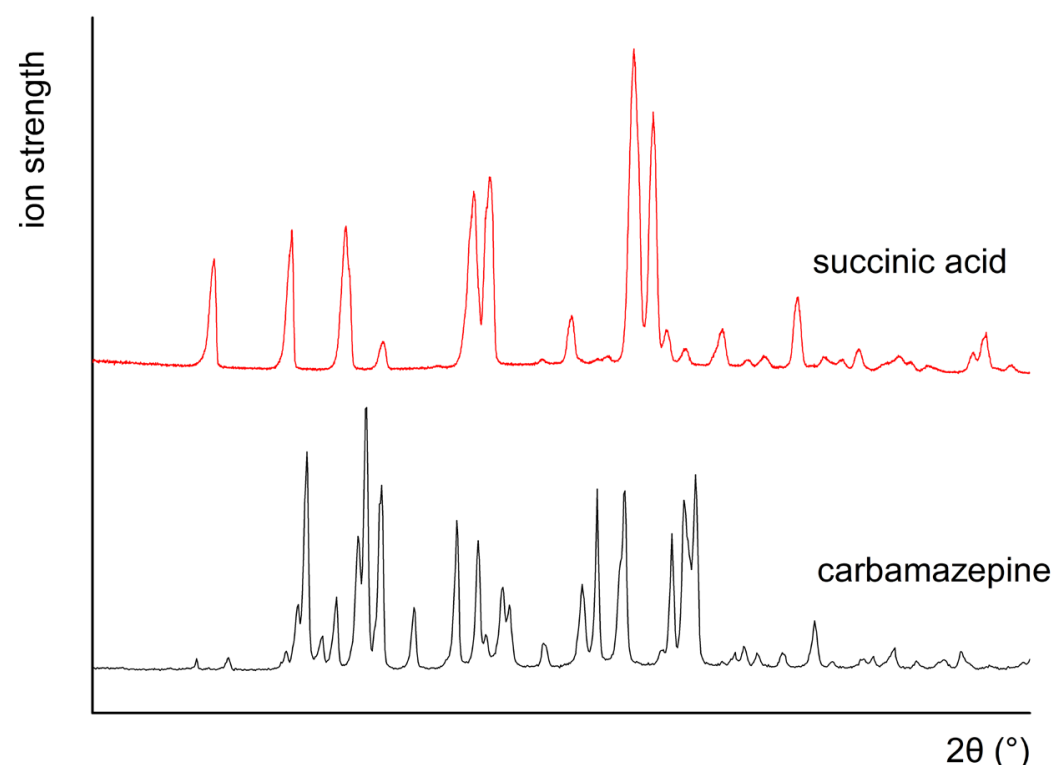

Figure 7. XRD patterns of carbamazepine and succinic acid.

\subsection{Sample PXRD Analysis}

The XRD of carbamazepine and succinic acid is shown in Figure 7, and the $\mathrm{XRD}$ of each cocrystal obtained according to the design model scheme is shown in Figures 8-12. Table 3 shows the $2 \theta$ and peak intensities of carbamazepine, succinic acid and the cocrystal of the two. The PXRD pattern results showed that a new crystal form was formed between carbamazepine and succinic acid. 


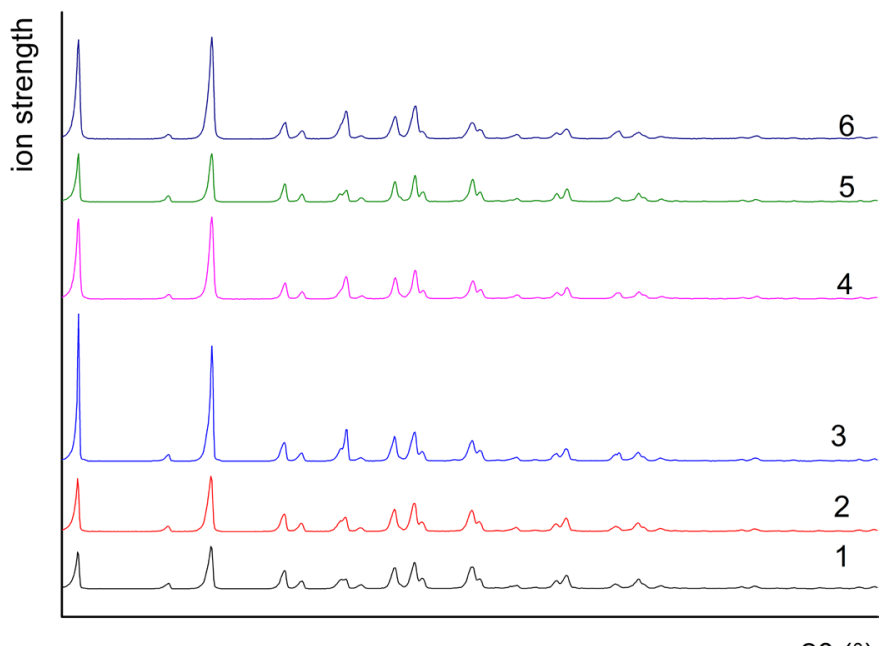

$2 \theta\left({ }^{\circ}\right)$

Figure 8. XRD patterns of samples 1 - 6 .

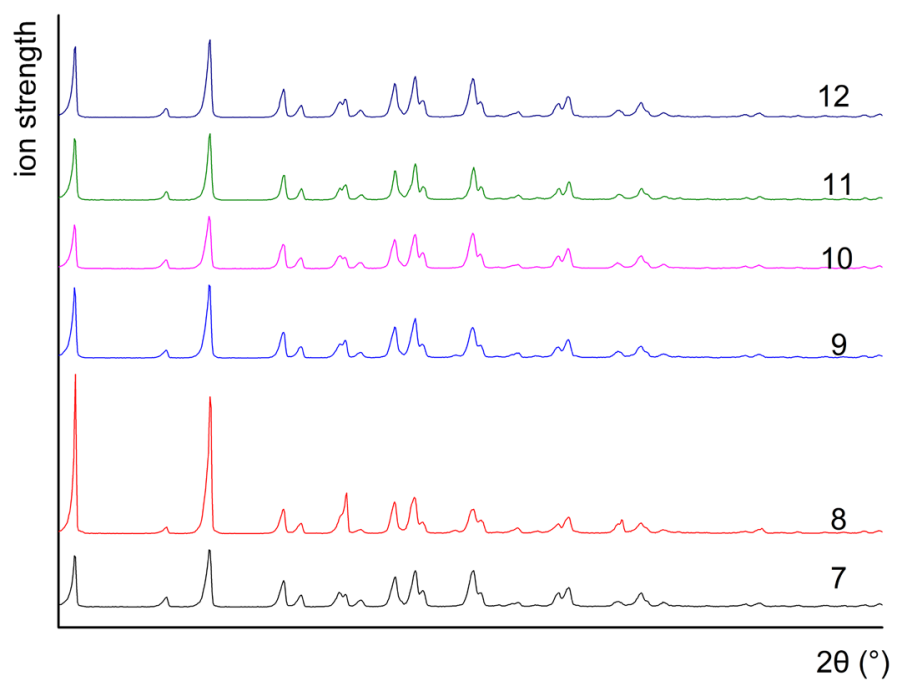

Figure 9. XRD patterns of samples $7-12$.

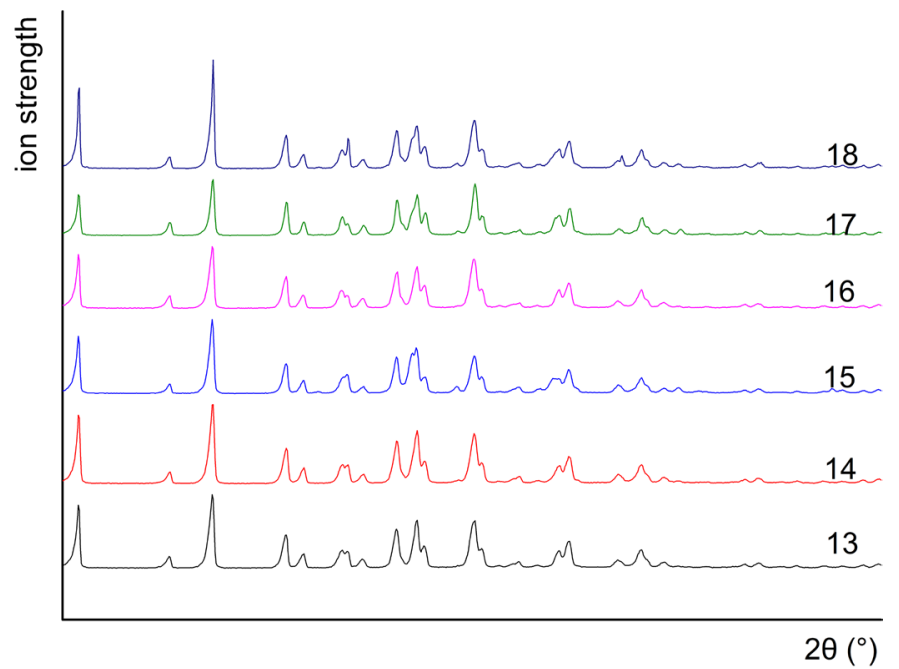

Figure 10. XRD patterns of samples 13 - 18 . 


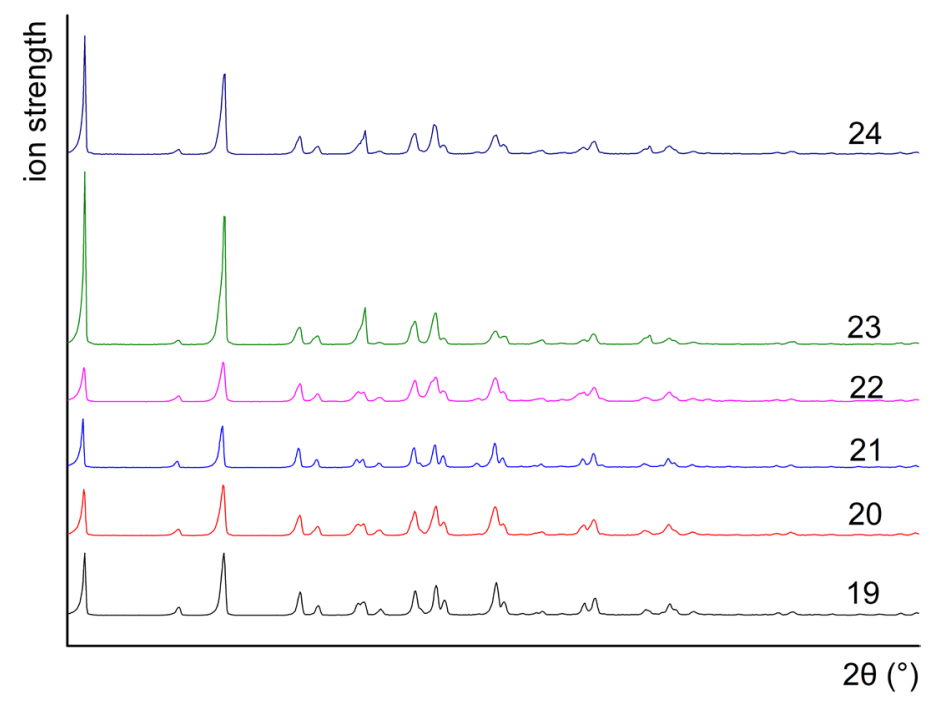

Figure 11. XRD patterns of samples $19-24$.

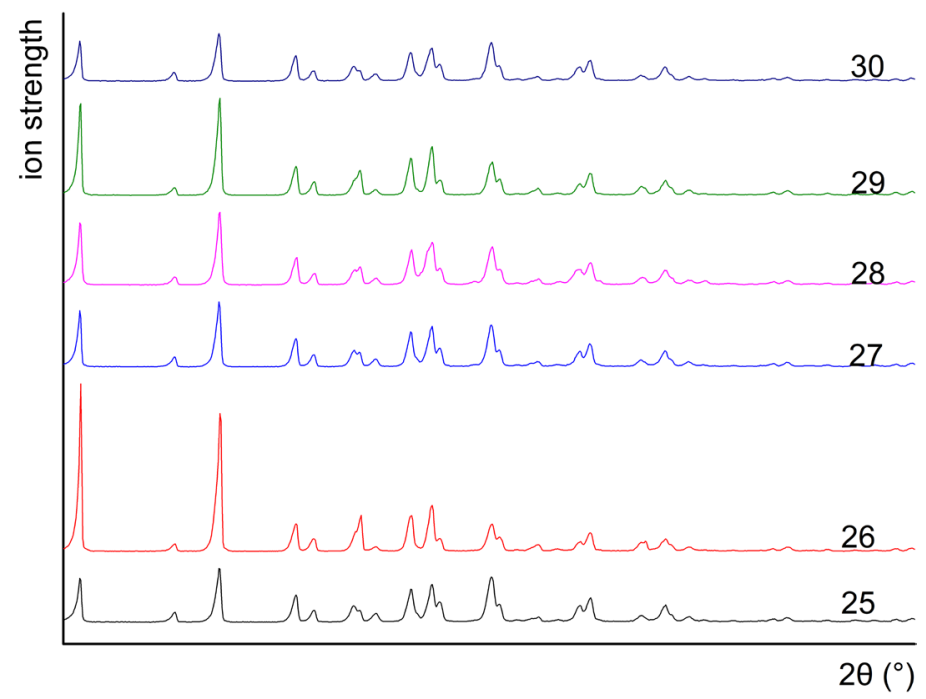

Figure 12. XRD patterns of samples $25-30$.

\section{Conclusions}

1) In this study, the Design-expert8 software was used to optimize the multiple regression model of CBZ-SA cocrystal yield, and the optimal crystallization conditions were predicted: when the crystallization time was $4 \mathrm{~h}$, material molar ratio was $\mathrm{CBA}: \mathrm{SA}=2: 1$, crystallization temperature at $30^{\circ} \mathrm{C}$ and a material concentration of $0.4 \mathrm{~mol} \cdot \mathrm{L}^{-1}$, the maximum yield of CBZ-SA cocrystal was $84.32 \%$.

2) The multiple regression model equations of the coding independent variables crystallization temperature, crystallization time, material molar ratio and material concentration were obtained: $\mathrm{R}_{1}=61.86+1.39 \mathrm{~A}+10.95 \mathrm{~B}+0.96 \mathrm{C}+$ $8.71 \mathrm{D}+1.26 \mathrm{AB}+0.84 \mathrm{AC}-0.39 \mathrm{AD}-0.68 \mathrm{BC}-0.71 \mathrm{BD}-0.25 \mathrm{CD}+0.086 \mathrm{~A}^{2}+$ $0.84 \mathrm{~B}^{2}+2.26 \mathrm{C}^{2}-3.45 \mathrm{D}^{2}$.

3) The characteristic peaks in the powder diffraction pattern of the CBZ-SA cocrystal had changed significantly, and the peak positions and peak shapes were 
completely different, at $2 \theta=5.68^{\circ}, 11.4^{\circ}, 15.32^{\circ}, 17^{\circ}, 17.2^{\circ}, 22.56^{\circ}, 26.68^{\circ}$, $29.76^{\circ}$. The characteristic peaks attributed to CBZ and SA are significantly smaller.

The current research demonstrated that the slurry crystallization technique can be an effective method in the production of cocrystals with appropriate selection of time, molar ratio, temperature, and concentration. CBZ-SA cocrystals were successfully formulated by integrating the cocrystal preparation technologies. In the preparation method, ethanol was selected as a solvent. Central composite design was successfully used to optimize the formulation and process parameters to get the desired cocrystal. The use of DoE and slurry crystallization to manufacture optimized CBZ-SA is an inexpensive, reproducible and precise method of manufacturing CBZ-SA. Quality of design $(\mathrm{QbD})$ here helps to understand the attributes related to preparation of cocrystal.

\section{Acknowledgements}

Authors sincerely acknowledge and express kind gratitude to all the authors of the publications and other contents used in the writing of this review paper entitled "Optimization of Carbamazepine-Succinic Acid Cocrystal Preparation using quality by design approach".

\section{Conflicts of Interest}

The authors declare no conflicts of interest regarding the publication of this paper.

\section{References}

[1] Bond, A.D. (2007) What Is a Cocrystal? CrystEngComm, 9, 833-834. https://doi.org/10.1039/b708112j

[2] Yousef, M.A.E. and Vangala, V.R. (2019) Pharmaceutical Cocrystals: Molecules, Crystals, Formulations, Medicines. Crystal Growth \& Design, 19, 7420-7438. https://doi.org/10.1021/acs.cgd.8b01898

[3] Thakuria, R., Delori, A., Jones, W., Lipert, M.P., Roy, L. and Rodríguez-Hornedo, N. (2013) Pharmaceutical Cocrystals and Poorly Soluble Drugs. International Journal of Pharmaceutics, 453, 101-125. https://doi.org/10.1016/j.ijpharm.2012.10.043

[4] Karagianni, A., Malamatari, M. and Kachrimanis, K. (2018) Pharmaceutical cocrystals: New Solid Phase Modification Approaches for the Formulation of APIs. Pharmaceutics, 10, 18. https://doi.org/10.3390/pharmaceutics10010018

[5] Duggirala, N.K., Perry, M.L., Almarsson, Ö. and Zaworotko, M.J. (2016) Pharmaceutical Cocrystals: Along the Path to Improved Medicines. Chemical Communications, 52, 640-655. https://doi.org/10.1039/C5CC08216A

[6] Bolla, G. and Nangia, A. (2016) Pharmaceutical Cocrystals: Walking the Talk. Chemical Communications, 52, 8342-8360. https://doi.org/10.1039/C6CC02943D

[7] Karimi-Jafari, M., Padrela, L., Walker, G.M. and Croker, D.M. (2018) Creating Cocrystals: A Review of Pharmaceutical Cocrystal Preparation Routes and Applications. Crystal Growth \& Design, 18, 6370-6387. https://doi.org/10.1021/acs.cgd.8b00933 
[8] Takata, N., Shiraki, K., Takano, R., Hayashi, Y. and Terada, K. (2008) Cocrystal Screening of Stanolone and Mestanolone Using Slurry Crystallization. Crystal Growth \& Design, 8, 3032-3037. https://doi.org/10.1021/cg800156k

[9] Kale, D.P., Zode, S.S. and Bansal, A.K. (2017) Challenges in Translational Development of Pharmaceutical Cocrystals. Journal of Pharmaceutical Sciences, 106, 457-470. https://doi.org/10.1016/j.xphs.2016.10.021

[10] Peltonen, L. (2018) Practical Guidelines for the Characterization and Quality Control of Pure Drug Nanoparticles and Nano-Cocrystals in the Pharmaceutical Industry. Advanced Drug Delivery Reviews, 131, 101-115. https://doi.org/10.1016/j.addr.2018.06.009

[11] Witika, B.A., Smith, V.J. and Walker, R.B. (2020) Quality by Design Optimization of Cold Sonochemical Synthesis of Zidovudine-Lamivudine Nanosuspensions. Pharmaceutics, 12, 367-384. https://doi.org/10.3390/pharmaceutics12040367

[12] Thakor, P., Yadav, B., Modhani, S. and Shastri, N.R. (2020) Preparation and Optimization of Nano-Sized Cocrystals Using Quality by Design Approach. CrystEngComm, 22, 2304-2314. https://doi.org/10.1039/C9CE01930H

[13] Chabalenge, B., Korde, S., Kelly, A.L., Neagu, D. and Paradkar, A. (2020) Understanding Matrix Assisted Continuous Cocrystallisation Using Data Mining Approach in Quality by Design (QbD). Crystal Growth \& Design, 20, 4540-4549. https://doi.org/10.1021/acs.cgd.0c00338 